\title{
Clinical utility of standard base excess in the diagnosis and interpretation of metabolic acidosis in critically ill patients
}

\author{
M. Park ${ }^{1}$, L.U. Taniguchi ${ }^{1}$, D.T. Noritomi ${ }^{1}$, A.B.Libório ${ }^{2}$, A.T. Maciel ${ }^{1}$ and \\ L.M. Cruz-Neto ${ }^{1}$
}

1Departamento de Emergência, Unidade de Terapia Intensiva, ${ }^{2}$ Departamento de Nefrologia, Hospital das Clínicas, Faculdade de Medicina, Universidade de São Paulo, São Paulo, SP, Brasil

Correspondence to: M. Park, Rua Francisco Preto, 46, Bloco 3, Apto 64, 05623-010 São Paulo, SP, Brasil

E-mail:mpark@uol.com.br

The aims of this study were to determine whether standard base excess (SBE) is a useful diagnostic tool for metabolic acidosis, whether metabolic acidosis is clinically relevant in daily evaluation of critically ill patients, and to identify the most robust acidbase determinants of SBE. Thirty-one critically ill patients were enrolled. Arterial blood samples were drawn at admission and $24 \mathrm{~h}$ later. SBE, as calculated by Van Slyke's $\left(\mathrm{SBE}_{\mathrm{VS}}\right)$ or Wooten's ( $\left.\mathrm{SBE}_{\mathrm{W}}\right)$ equations, accurately diagnosed metabolic acidosis ( $A \cup C=0.867,95 \% \mathrm{Cl}=0.690-1.043$ and $\mathrm{AUC}=0.817,95 \% \mathrm{Cl}=0.634-0.999$, respectively). SBE $\mathrm{vs}$ was weakly correlated with total SOFA $(r=-0.454, P<0.001)$ and was similar to $\mathrm{SBE}_{W}(r=-0.482, \mathrm{P}<0.001)$. All acid-base variables were categorized as $\mathrm{SBE}_{\mathrm{VS}}<-2 \mathrm{mEq} / \mathrm{L}$ or $\mathrm{SBE}_{\mathrm{VS}}<-5 \mathrm{mEq} / \mathrm{L}$. SBE $\mathrm{Vs}_{\mathrm{Vs}}<-2 \mathrm{mEq} / \mathrm{L}$ was better able to identify strong ion gap acidosis than $\mathrm{SBE} \mathrm{Vs}^{<-5} \mathrm{mEq} /$ $\mathrm{L}$; there were no significant differences regarding other variables. To demonstrate unmeasured anions, anion gap (AG) corrected for albumin $\left(A G_{A}\right)$ was superior to $A G$ corrected for albumin and phosphate $\left(A G_{A+P}\right)$ when strong ion gap was used as the standard method. Mathematical modeling showed that albumin level, apparent strong ion difference, $A G_{A}$, and lactate concentration explained $\mathrm{SBE}_{\mathrm{VS}}$ variations with an $\mathrm{R}^{2}=0.954$. $\mathrm{SBE}_{\mathrm{Vs}}$ with a cut-off value of $<-2 \mathrm{mEq} / \mathrm{L}$ was the best tool to diagnose clinically relevant metabolic acidosis. To analyze the components of $\mathrm{SBE}_{\mathrm{Vs}}$ shifts at the bedside, $\mathrm{AG}_{\mathrm{A}}$, apparent strong ion difference, albumin level, and lactate concentration are easily measurable variables that best represent the partitioning of acid-base derangements.

Key words: Metabolic acidosis; Clinical outcome; Strong ion gap; Standard base excess; Van Slyke equation; Sequential organ failure assessment

Publication supported by FAPESP.

Received July 12, 2007. Accepted October 25, 2007

\section{Introduction}

Various contemporary studies of acid-base physiology that quantify previously described acid-base derangements have been published recently $(1,2)$. These studies have refined our understanding of the basic mechanisms that control blood $\mathrm{pH}$ in health and disease, and have described the epidemiology and clinical significance of acidbase imbalances in more detail than was previously possible (3-5). In the current literature, it has been established with mathematical calculation that the modern (quantitative) and traditional (descriptive) approaches are easily interchangeable at a fundamental level. This interchange has resulted in clarification of the limitations of each approach and has revealed how a combinatorial approach can be used to achieve a more complete understanding of clinical acid-base physiology $(3,6)$.

At the bedside of a critically ill patient, it is important to note that there appears to be a difference in physiologic variables and outcomes between patients with respiratory acidosis and those with metabolic acidosis, leading some investigators to hypothesize that it is the cause of acidosis, rather than the acidosis per se, that drives the association with clinical outcomes (6). When taking metabolic acidosis into account, there are many possible mechanisms involved, and it seems that there is a different reflex on the 
outcome based on the mechanism, again suggesting the concept that the cause of acidosis is more important than the acidosis per se (7-10).

Standard base excess (SBE) has been used to identify metabolic acidosis (4) and to determine the prognosis of critically ill patients at the time of admission to the intensive care unit $(8,9,11)$. The SBE is therefore a useful tool at the bedside, despite the fact that many complex metabolic disturbances cannot be disclosed by the SBE alone (4). Based on the current literature, there are two different methodologies with which to calculate the SBE, and there are two different cut-offs of SBE (<-2 mEq/L $(6,7)$ or $<-5$ $\mathrm{mEq} / \mathrm{L}(3))$ that are used to discriminate metabolic acidosis. However, there is no concise definition of these issues.

The severity of disease in critically ill patients can be quantified by the number of organ failures added to the severity of dysfunction of each organ. The sequential organ failure assessment (SOFA) score was created to evaluate organ failure, focusing on morbidity instead of mortality (12). The SOFA score was developed through a consensus process (13) and subsequently validated in a larger population of 1449 critically ill patients (14). The total SOFA is composed of scores from six organ systems (respiratory, cardiovascular, hepatic, coagulation, renal, and neurologic), graded from 0 to 4 according to the degree of dysfunction/failure (15). The SOFA score was initially described in septic patients (13). During the last decade, however, SOFA scoring has been adapted to other situations $(14,16)$. The progressive elevation of the total SOFA score is a marker of poor outcome in the daily evaluation of critically ill patients (17), and by $48 \mathrm{~h}$ after admission, the highest SOFA score is a clinically meaningful outcome marker (18). The total SOFA score is thus a reliable tool to quantify on a daily basis the severity of disease in critically ill patients (12).

The aims of this study were to determine whether the SBE was a useful tool to evaluate metabolic acidosis and whether it was clinically relevant in the daily evaluation of critically ill patients. In order to show the clinical relevancy of daily SBE evaluation, the total SOFA score was used as a tool to quantify the severity of disease of critically ill patients. In addition, we ascertained the best methodology by which to calculate the SBE, the best value of SBE by which to define metabolic acidosis, and identified the best metabolic determinants of SBE, according to the traditional and modern acid-base concepts.

\section{Material and Methods}

From February to March 2004, 31 patients consecutively admitted to the 7 beds of the intensive care unit of
Hospital das Clínicas, a tertiary care teaching hospital in Brazil, were enrolled in the study. After approval of the protocol, written informed consent was obtained from the patient or next-of-kin as per the hospital's Ethics Committee recommendations. Arterial blood samples were drawn from the arterial line both at the time of admission and $24 \mathrm{~h}$ later. Data such as age, acute physiology and chronic health evaluation (APACHE) II score, total SOFA score, weight, height, diagnosis, vasopressor and/or inotropic use, fluid management, renal replacement requirements, mechanical ventilation requirements, and clinical outcomes were also recorded. Albumin, phosphate, and serum $\mathrm{Mg}^{2+}$ levels were analyzed by colorimetric techniques, and other serum electrolyte levels were measured with an ion-selective electrode. Arterial blood gases and lactate concentrations were measured by the OMNI analyzer (Roche Diagnostics System, F. Hoffmann, La Roche Ltd., Basel, Switzerland).

Each patient had 2 measures of acid-base status analyzed. Thus, 62 samples were obtained. All mathematical calculations were performed following standard formulas (see Appendix).

Two levels of SBE, as calculated by Van Slyke's equation, have been reported to recognize metabolic acidosis $\left(\mathrm{SBE}_{\mathrm{Vs}}\right)$ : an $\mathrm{SBE}_{\mathrm{Vs}}<-2 \mathrm{mEq} / \mathrm{L}(6,7)$ and an $\mathrm{SBE}_{\mathrm{Vs}}<-5$ $\mathrm{mEq} / \mathrm{L}$ (3). A physicochemical analysis of the groups categorized by these values of $\mathrm{SBE}_{\mathrm{Vs}}$ was performed. Likewise, arterial blood sample values were extracted from normal volunteers, and their 2.5 th and 97.5 th percentiles were established as normal ranges.

Recently, Wooten $(19,20)$ have developed a new correction to the $\mathrm{SBE}\left(\mathrm{SBE}_{\mathrm{w}}\right)$ based on albumin and phosphate variations, a common scenario in critically ill patients. In order to show the difference between Van Slyke's and Wooten's equations, we measured the correlation and agreement for both values. For the diagnostic evaluation of SBE, the sensitivity, specificity, and accuracy were calculated with both the Van Slyke's and Wooten's equations, taking into account the physicochemical methodology as the gold standard for the diagnosis of metabolic acidosis. Subsequently, the diagnosis of metabolic acidosis with the two different cut-off levels of $\mathrm{SBE}_{\mathrm{Vs}}$ previously described ( $<-2 \mathrm{mEq} / \mathrm{L}$ and $<-5 \mathrm{mEq} / \mathrm{L}$ ) were compared to the diagnosis of metabolic acidosis by the physicochemical (quantitative) methodology.

The severity of the disease was correlated to several acid-base variables using the daily total SOFA score, in order to recognize which acid-base variables were clinically relevant at the bedside. Newer and more complex acid-base variables were compared to simpler and more classic ones, in order to show the best methodology for 
partitioning the acid-base metabolism.

Data distribution was analyzed with the KolmogorovSmirnov goodness-of-fit model, and later shown as medians and an interquartile range. Single medians were compared between groups using the Mann-Whitney U-test, and the within-group comparison between $\mathrm{SBE}_{\mathrm{vs}}$ and $\mathrm{SBE}_{W}$ was performed with the Wilcoxon test. Sensitivity and specificity, as well as the accuracy (area under the curve of the receiver operator characteristic (ROC) curve with a $95 \%$ confidence interval), were calculated for $\mathrm{SBE}_{\mathrm{vs}}$ and $\mathrm{SBE}_{W}$. The ROC curve was also used to analyze the anion gap corrected for albumin $\left(\mathrm{AG}_{\mathrm{A}}\right)$, and the anion gap corrected for albumin and phosphate $\left(A G_{A+P}\right)$ as a discriminator of a strong ion gap (SIG) acidosis. The correlation analysis was carried out with Spearman's test and agreement was analyzed with the Bland-Altman plot. The commercially available SPSS, version 10.0 (Chicago, IL, USA) was used, designating $P<0.05$ as a significant level.

\section{Results}

The general characteristics of the patients at the time of admission, the main support measures, the clinical outcomes, and the diagnoses are shown in Table 1. The ROC curves of $\mathrm{SBE}_{\mathrm{vs}}$ and $\mathrm{SBE}_{\mathrm{W}}$ used to diagnose metabolic acidosis are shown in Figure 1. Figure 2 shows the correlation and agreement between the SBE, as calculated by Van Slyke's and Wooten's equations. In Table 2, the biochemical results from the arterial blood samples are split into groups according to the two pre-selected cut-off levels of $\mathrm{SBE}_{\mathrm{Vs}}$ (-2 and $\left.-5 \mathrm{mEq} / \mathrm{L}\right)$. Age, APACHE II score, and total SOFA score are also shown for each group. The metabolic component of acid-base derangements was classified according to Stewart's physicochemical approach variables (21) that is, an apparent strong ion difference $\left(\mathrm{SID}_{\mathrm{a}}\right)$ acidosis, an SIG acidosis, acidosis associated with an excess of albumin and inorganic phosphorus $\left(\mathrm{P}_{\mathrm{i}}\right.$; derived from phosphate (see Appendix)), and the overlap of these three components. Table 3 shows the classification and the number of samples that fit the criteria of a specific acidosis according to Stewart's physicochemical approach. The samples were split according to $\mathrm{SBE}_{\mathrm{Vs}}$ cut-offs. The normal values considered were those between the 2.5 th and 97.5th percentiles obtained from the venous blood samples of normal volunteers. Only two measures did not show any metabolic acidosis according to the physicochemical approach. Therefore, an $\mathrm{SBE}_{\mathrm{Vs}}<-5 \mathrm{mEq} / \mathrm{L}$ and an $\mathrm{SBE}_{\mathrm{VS}}<-2 \mathrm{mEq} / \mathrm{L}$ were able to detect metabolic acidosis in $100 \%$ of the samples (Table 3 ).

The $A G_{A}$ and $A G_{A+P}$ were analyzed individually as possible surrogates of the SIG method to detect unmea- sured anions. The sensitivities, specificities, and accuracies are shown in Table 4. These reports represent the entire group of measurements and are stratified for the different cut-offs of $\mathrm{SBE}_{\mathrm{vs}}$. Figure 3 shows the correlation and agreement between the SIG and the $A_{A}$ and the correlation and agreement between the SIG and the $A_{A+P}$. In Table 5, the main acid-base variables were correlated to the total SOFA of the day when the blood sample was obtained.

Since $\mathrm{SBE}_{\mathrm{Vs}}$ is an appropriate tool to diagnose metabolic acidosis, we built several models using a multilinear regression with $\mathrm{SBE}_{\mathrm{Vs}}$ as a dependent factor. The results, in terms of a determinant coefficient, using the following 5 variables as independent factors, were as follows: 1) SIG,

Table 1. General characteristics of patients at admission, support measures, outcome, and diagnosis.

Characteristics at admission

Age (years)

$46(33,59)$

APACHE II

Total SOFA

Gender (N (\%), male/female)

Weight $(\mathrm{kg})$

Height (cm)

Mean arterial pressure $(\mathrm{mmHg})$

Heart rate $(\mathrm{bpm})$

Temperature (Celsius)

$18(14,21)$

$5(2,8)$

$24(77 \%) / 7(23 \%)$

$75(63,80)$

$170(160,175)$

$90(77,100)$

$93(82,110)$

$37.0(36.3,37.5)$

Support and outcome

Norepinephrine ( $\left.\mathrm{N}(\%) / \mathrm{\mu g}^{-1} \mathrm{~kg}^{-1} \mathrm{~min}^{-1}\right)$

Dobutamine ( $\mathrm{N}(\%) / \mathrm{ug}^{-1} \mathrm{~kg}^{-1} \mathrm{~min}^{-1}$ )

Fluids received $(\mathrm{mL})$

Diuresis $(\mathrm{mL})$

Renal dysfunction ( $\mathrm{Cr} \geq 2.5 \mathrm{mg} / \mathrm{dL}, \mathrm{N}(\%)$ )

Chronic renal failure ( $\mathrm{N}(\%)$ )

Dialysis (N (\%))

Mechanical ventilation ( $\mathrm{N}(\%))$

Length of stay (days)

$6(20 \%) / 0.6$

$3(10 \%) / 13$

$5000(2300,13749)$

$3250(0,4375)$

$12(39 \%)$

$4(13 \%)$

$11(35 \%)$

$22(71 \%)$

$5(4,8)$

Survivors (N (\%))

$27(87 \%)$

Cause of ICU admission

Respiratory failure (N (\%))

$9(29 \%)$

Acute lung injury (N (\%))

$6(19 \%)$

Acute respiratory distress syndrome (N (\%)) $3(10 \%)$

Septic shock (N (\%))

$8(27 \%)$

Hypovolemic shock (N (\%))

Cardiogenic shock ( $\mathrm{N}(\%)$ )

Severe sepsis (N (\%))

$4(13 \%)$

$2(6 \%)$

$2(6 \%)$

Neurological (N (\%))

$4(13 \%)$

High risk postoperative (N (\%))

$2(6 \%)$

Data are reported as median and interquartile range or number of patients and percentage of the total sample of patients $(\mathrm{N}=$ 31). APACHE II is an acute physiology and chronic health evaluation score, ranging from 0 to 72 . SOFA is a sequential organ failure assessment score, ranging from 0 to 24. Support measures refer to the first day in the intensive care unit (ICU). 
SID , the sum of albumin $+P_{i}$, and lactate $\left.\left(R^{2}=0.958\right) ; 2\right)$ SIG, SID , and lactate $\left(R^{2}=0.890\right)$; 3) SIG, SID , lactate, and albumin ( $\left.R^{2}=0.911\right)$; 4) $A G_{A}$, chloride, lactate, and albumin $\left(R^{2}=0.640\right)$, and 5) $A G_{A}, S_{a}$, lactate, and albumin $\left(R^{2}=0.954\right)$.

\section{Discussion}

In our study, $\mathrm{SBE}_{\mathrm{vs}}$ was the best acid-base variable correlated with the daily total SOFA. An SBE $\mathrm{Vs}_{\mathrm{s}}<-2 \mathrm{mEq} / \mathrm{L}$ was better able to differentiate SIG acidosis than an $\mathrm{SBE}_{\mathrm{VS}}$ $<-5 \mathrm{mEq} / \mathrm{L}$, with no significant differences regarding the other variables. To show unmeasured anions, $A_{A}$ was superior to the $A G_{A+P}$ when the SIG was taken as the standard method. A mathematical model showed that variations of albumin, $\mathrm{SID}_{\mathrm{a}}, \mathrm{AG}_{\mathrm{A}}$, and lactate accounted for the $S B E_{V S}$ variations with an $R^{2}=0.954$.

\section{Clinical relevance of standard base excess}

Acid-base derangements are extremely common in critically ill patients, and their clinical significance makes their precise detection and interpretation a necessity (6). Using the SBE as the marker for metabolic acidosis can lead to a misdiagnosis in the absence of metabolic acidosis $(4,22)$. However, the diagnosis of metabolic acidosis using the SBE seems to be clinically relevant in terms of predicting clinical outcome $(8,9,11)$.

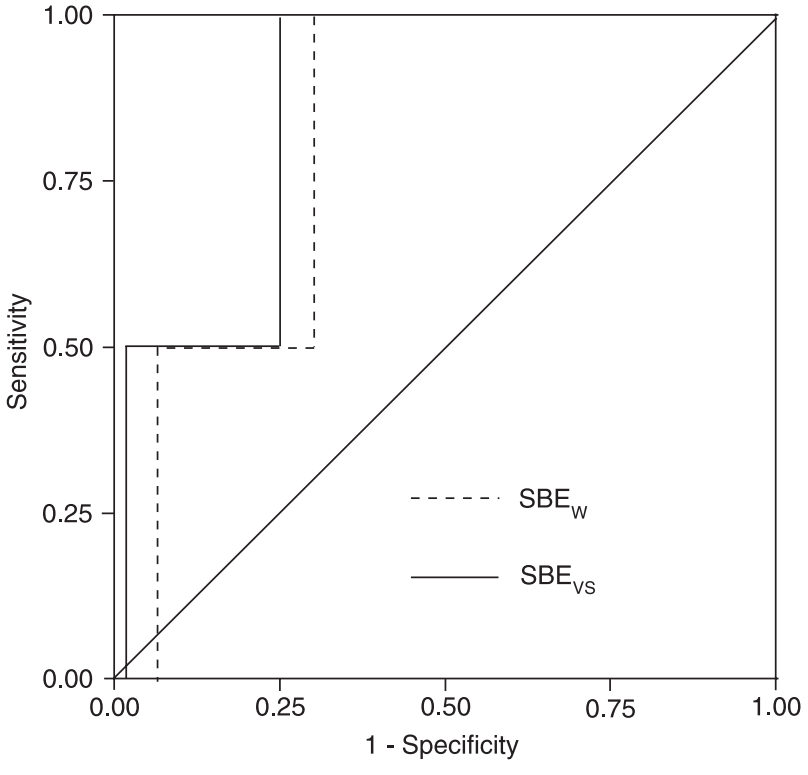

Figure 1. Receiver operator characteristic curve of standard base excess calculated by Van Slyke's equation (SBEVs, area under the curve $=0.867, \mathrm{Cl} 95 \%=0.690-1.043$ ) and Wooten's equation $\left(\mathrm{SBE}_{W}\right.$, area under the curve $=0.817$, CI95\% $=0.634$ $0.999)$ formulas to disclose metabolic acidosis diagnosed by Stewart's methodology. Using the Youden's $(\mathrm{J})$ index the best value of $\mathrm{SBE}_{V s}$ to disclose metabolic acidosis was -2.7 with sensitivity of $100 \%$ and specificity of $75 \%$, and the best value of $\mathrm{SBE}_{W}$ to disclose metabolic acidosis was -3.6 with sensitivity of $100 \%$ and specificity of $70 \%$.

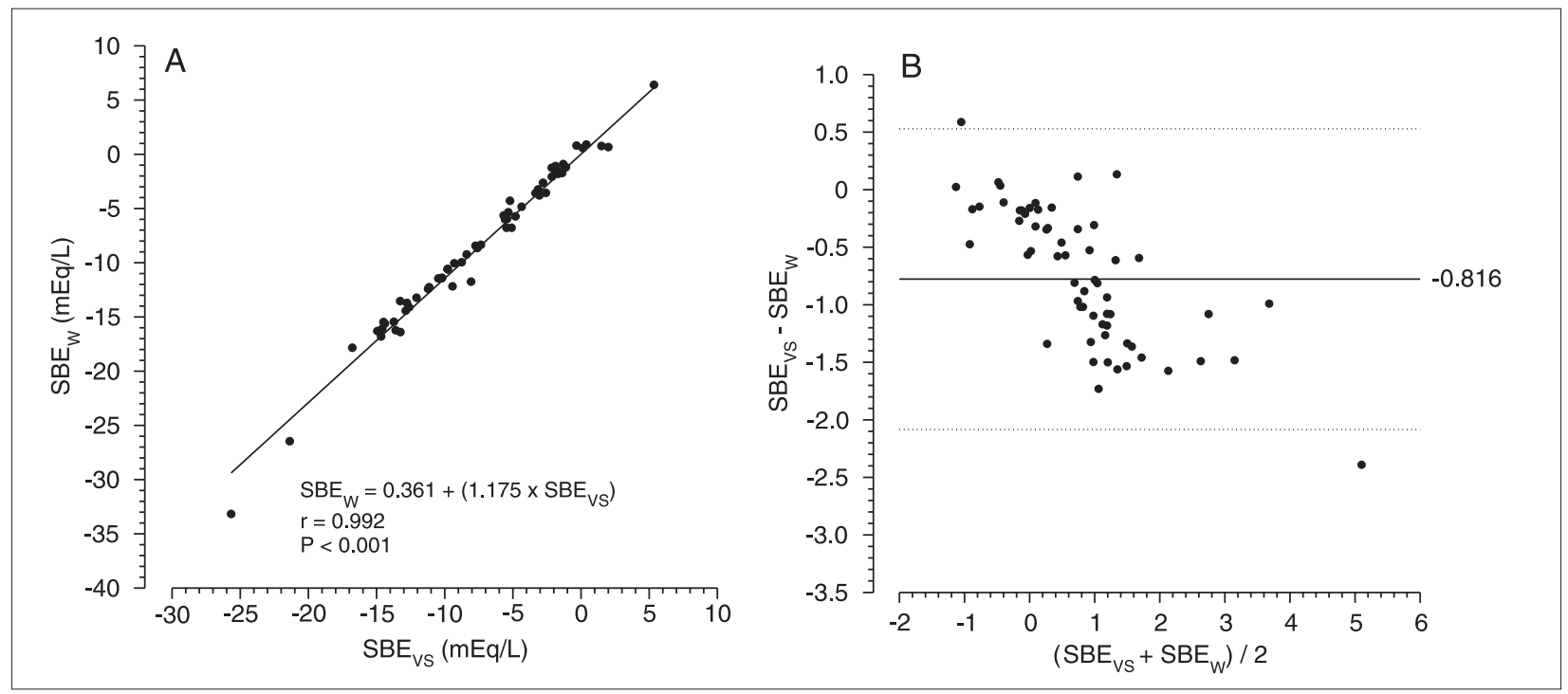

Figure 2. Correlation and agreement between the standard base excess calculated by Van Slyke's (SBEVs) and Wooten's (SBEW) equations. $A$, Correlation and equation derived from the linear regression between the $\mathrm{SBE}_{\mathrm{Vs}}$ and $\mathrm{SBE}_{\mathrm{w}}$ equations. $B$, Bland Altman plot disclosing the agreement between the $\mathrm{SBE}_{V S}$ and $\mathrm{SBE}_{W}$ equations. The number shown on the right side of the plot is the bias. 
Table 2. Clinical and biochemical characteristics of patients with standard base excess cut-off values of -5 or $-2 \mathrm{mEq} / \mathrm{L}$, and normal values obtained from healthy volunteers.

\begin{tabular}{|c|c|c|c|c|c|c|}
\hline Characteristics & $\begin{array}{c}\mathrm{SBE}_{\mathrm{Vs}}<-5 \mathrm{mEq} / \mathrm{L} \\
(\mathrm{N}=38)\end{array}$ & $\begin{array}{c}\mathrm{SBE}_{\mathrm{Vs}} \geq-5 \mathrm{mEq} / \mathrm{L} \\
(\mathrm{N}=24)\end{array}$ & $\begin{array}{c}\mathrm{SBE}_{\mathrm{Vs}}<-2 \mathrm{mEq} / \mathrm{L} \\
(\mathrm{N}=48)\end{array}$ & $\begin{array}{c}\text { SBE }_{\mathrm{Vs}} \geq-2 \mathrm{mEq} / \mathrm{L} \\
(\mathrm{N}=14)\end{array}$ & $\begin{array}{l}\text { Controls } \\
(N=14)\end{array}$ & $\begin{array}{c}\text { Percentiles } \\
2.5 \text { th } \Leftrightarrow 97.5 \text { th }\end{array}$ \\
\hline Age (years) & $46(33,76)$ & $42(34,53)$ & $46(33,71)$ & $42(33,49)$ & $43(33,51)$ & - \\
\hline APACHE II & $21(17,24)^{*}$ & $14(10,17)$ & $20(16,24)^{* *}$ & $14(10,16)$ & - & - \\
\hline SOFA & $6.0(4.3,9.8)^{*}$ & $2.5(1.0,5.0)$ & $5.0(3.0,8.0)^{\star *}$ & $3.0(1.5,4.0)$ & - & - \\
\hline $\mathrm{pH}$ & $7.32(7.21,7.36)^{*}$ & $7.41(7.37,7.47)$ & $7.33(7.24,7.39)^{\star *}$ & $7.43(7.40,7.49)$ & - & - \\
\hline $\mathrm{PaCO}_{2}(\mathrm{mmHg})$ & $28(24,34)^{*}$ & $35(33,38)$ & $30(25,37)^{\star \star}$ & $35(31,37)$ & - & - \\
\hline $\mathrm{SBE}_{\mathrm{Vs}}(\mathrm{mEq} / \mathrm{L})$ & $-10.3(-13.6,7.74)^{*,++}$ & $-1.9(-2.9,-0.7)^{+,++}$ & $-9.4(-13.1,-5.27)^{* *}$ & $-1.2(-1.7,0.4)$ & $0.3(-1.7,1.8)$ & $-3.2 \Leftrightarrow 2.2$ \\
\hline $\mathrm{SBE}_{W}(\mathrm{mEq} / \mathrm{L})$ & $-12.0(-15.5,-8.7)^{\star}$ & $-1.7(-3.4,-0.2)^{+}$ & $-10.6(-14.3,-5.7)^{\star *}$ & $-1.0(-1.7,0.8)$ & $-0.9(-3.0,1.9)$ & $-3.9 \Leftrightarrow 3.0$ \\
\hline $\mathrm{Na}(\mathrm{mEq} / \mathrm{L})$ & $139(135,144)$ & $137(136,143)$ & $140(135,144)$ & $137(135,138)$ & - & - \\
\hline $\mathrm{Cl}(\mathrm{mEq} / \mathrm{L})$ & $106(102,111)^{*}$ & $99(98,104)$ & $104(99,110)^{\star *}$ & $99(97,102)$ & - & - \\
\hline Albumin (g/dL) & $2.3(2.0,2.8)^{\star}$ & $3.0(2.4,3.2)$ & $2.4(2.0,3.0)$ & $2.8(2.4,3.1)$ & - & - \\
\hline Phosphate (mg/dL) & $3.8(2.7,5.8)$ & $3.0(2.3,3.9)$ & $3.8(2.5,5.2)$ & $3.1(2.3,3.7)$ & - & - \\
\hline Albumin $+\mathrm{P}_{\mathrm{i}}(\mathrm{mEq} / \mathrm{L})$ & $8.8(6.6,10.4)^{*}$ & $9.8(8.6,11.0)$ & $8.9(7.0,10.7)$ & $9.3(8.4,9.8)$ & $14.3(12.8,14.6)$ & $11.3 \Leftrightarrow 15.3$ \\
\hline Lactate $(\mathrm{mEq} / \mathrm{L})$ & $1.2(1.0,1.9)$ & $1.4(1.0,2.3)$ & $1.2(1.1,1.9)$ & $1.4(0.8,2.3)$ & - & - \\
\hline Creatinine (mg/dL) & $1.9(0.9,3.8)^{*}$ & $0.9(0.7,1.4)$ & $1.4(0.8,3.8)$ & $1.0(0.7,1.1)$ & - & - \\
\hline $\mathrm{AG}_{\mathrm{A}}(\mathrm{mEq} / \mathrm{L})$ & $28(24,31)^{*}$ & $23(19,27)$ & $27(24,31)^{\star *}$ & $20(15,22)$ & $15.5(14.0,17.0)$ & $12.2 \Leftrightarrow 19.6$ \\
\hline $\mathrm{AG}_{\mathrm{A}+\mathrm{P}}(\mathrm{mEq} / \mathrm{L})$ & $21(17,24)^{*}$ & $18(13,22)$ & $21(18,24)^{\star *}$ & $15(11,17)$ & $13(10,15)$ & $8 \Leftrightarrow 19$ \\
\hline $\mathrm{SIG}(\mathrm{mEq} / \mathrm{L})$ & $14(10,19)^{*}$ & $11(6,15)$ & $14(11,19)^{\star \star}$ & $8(3,10)$ & $2.2(1.2,3.6)$ & $-1.1 \Leftrightarrow 6.1$ \\
\hline $\mathrm{SID}_{\mathrm{a}}(\mathrm{mEq} / \mathrm{L})$ & $39(35,42)^{*}$ & $45(40,47)$ & $40(36,43)$ & $41(40,45)$ & $41.0(39.8,42.0)$ & $38.9 \Leftrightarrow 48.2$ \\
\hline
\end{tabular}

Data are reported as median and interquartile range within parentheses. SBEVs and SBEW = standard base excess calculated by Van Slyke's and Wooten's equations, respectively. APACHE II = acute physiology and chronic health evaluation score, ranging from 0 to 72 ; SOFA = sequential organ failure assessment score, ranging from 0 to $24 ; P_{i}=$ inorganic phosphorus; $A G_{A}, A_{A+P}=$ anion gap corrected for albumin and anion gap corrected for albumin and phosphate, respectively; $\mathrm{SIG}=$ strong ion gap; $\mathrm{SID}_{\mathrm{a}}=$ apparent strong ion difference. ${ }^{*} \mathrm{P}<0.05$ vs $\mathrm{SBE} \geq-5 \mathrm{mEq} / \mathrm{L} ;{ }^{* *} \mathrm{P}<0.05$ vs $\mathrm{SBE} \geq-2 \mathrm{mEq} /$ $\mathrm{L} ;{ }^{+} \mathrm{P}<0.05$ vs SBE $\geq-2 \mathrm{mEq} / \mathrm{L} ;{ }^{++} \mathrm{SBE}$ vs was not statistically different from SBEW (Wilcoxon test). All variables of SBE <-5 mEq/L column were tested against variables of $\mathrm{SBE}<-2 \mathrm{mEq} / \mathrm{L}$ column, and the same was done with $\mathrm{SBE} \geq-5 \mathrm{mEq} / \mathrm{L}$ and $\mathrm{SBE} \geq-2 \mathrm{mEq} / \mathrm{L}$ columns.

Table 3. Classification of acid-base measures using the physicochemical criteria according to the standard base excess (SBE) cut-offs

\begin{tabular}{|c|c|c|c|c|c|}
\hline Measurement categories & $\begin{array}{c}\mathrm{SBE}_{\mathrm{vs}}<-5 \\
\mathrm{mEq} / \mathrm{L}(\mathrm{N}=38)\end{array}$ & $\begin{array}{c}\mathrm{SBE}_{\mathrm{vs}} \geq-5 \\
\mathrm{mEq} / \mathrm{L}(\mathrm{N}=24)\end{array}$ & $\begin{array}{c}\mathrm{SBE}_{\mathrm{vs}}<-2 \\
\mathrm{mEq} / \mathrm{L}(\mathrm{N}=48)\end{array}$ & $\begin{array}{c}\mathrm{SBE}_{\mathrm{vs}} \geq-2 \\
\mathrm{mEq} / \mathrm{L}(\mathrm{N}=14)\end{array}$ & $\begin{array}{c}\text { Total } \\
(\mathrm{N}=62)\end{array}$ \\
\hline \multicolumn{6}{|l|}{ SIG acidosis } \\
\hline SIG >6.1 (N (\%)) & $35(92 \%)$ & $18(75 \%)$ & $44(92 \%)$ & $9(64 \%)$ & $53(85 \%)$ \\
\hline $\mathrm{SIG}>6.1$ and $\mathrm{SID}_{\mathrm{a}}<38.9(\mathrm{~N}(\%))$ & $17(45 \%)$ & $0(0 \%)$ & $17(35 \%)$ & $0(0 \%)$ & $17(27 \%)$ \\
\hline $\mathrm{SIG}>6.1$ and $\mathrm{SID}_{\mathrm{a}} \geq 38.9(\mathrm{~N}(\%))$ & $18(47 \%)$ & $18(75 \%)$ & $27(56 \%)$ & $9(64 \%)$ & $36(58 \%)$ \\
\hline \multicolumn{6}{|l|}{ SID acidosis } \\
\hline $\mathrm{SID}_{\mathrm{a}}<38.9(\mathrm{~N}(\%))$ & $20(53 \%)$ & $4(17 \%)$ & $21(44 \%)$ & $3(21 \%)$ & $24(39 \%)$ \\
\hline $\mathrm{SID}_{\mathrm{a}}<38.9$ and $\mathrm{SIG} \leq 6.1(\mathrm{~N}(\%))$ & $3(8 \%)$ & $4(17 \%)$ & $4(8 \%)$ & $3(21 \%)$ & $7(11 \%)$ \\
\hline $\mathrm{SID}_{\mathrm{a}}<38.9$ and SIG >6.1 (N (\%)) & $17(45 \%)$ & $0(0 \%)$ & $17(35 \%)$ & $0(0 \%)$ & $17(27 \%)$ \\
\hline \multicolumn{6}{|l|}{ Albumin + inorganic phosphorus derangements } \\
\hline$A+P_{i}>15.3(N(\%))$ & $0(0 \%)$ & $0(0 \%)$ & $0(0 \%)$ & $0(0 \%)$ & $0(0 \%)$ \\
\hline$A+P_{i}<11.3(N(\%))$ & $32(84 \%)$ & $19(79 \%)$ & $38(79 \%)$ & $13(93 \%)$ & $51(82 \%)$ \\
\hline $\mathrm{A}+\mathrm{P}_{\mathrm{i}}<11.3$ and $\mathrm{SIG}>6.1(\mathrm{~N}(\%))$ & $30(79 \%)$ & $13(54 \%)$ & $35(73 \%)$ & $8(57 \%)$ & $43(69 \%)$ \\
\hline $\mathrm{A}+\mathrm{P}_{\mathrm{i}}<11.3$ and $\mathrm{SID}_{\mathrm{a}}<38.9(\mathrm{~N}(\%))$ & $18(47 \%)$ & $4(17 \%)$ & $19(40 \%)$ & $3(21 \%)$ & $22(35 \%)$ \\
\hline$A+P_{i}<11.3$ and $S I G>6.1$ and $\operatorname{SID}_{a}<38.9(N(\%))$ & $16(42 \%)$ & $0(0 \%)$ & $16(33 \%)$ & $0(0 \%)$ & $16(26 \%)$ \\
\hline \multicolumn{6}{|l|}{ Absence of acidosis } \\
\hline $\mathrm{SIG} \leq 6.1$ and $\mathrm{SID}_{\mathrm{a}} \geq 38.9(\mathrm{~N}(\%))$ & $0(0 \%)$ & $2(8 \%)^{*}$ & $0(0 \%)$ & $2(14 \%)^{*}$ & $2(3 \%)$ \\
\hline \multicolumn{6}{|l|}{ Capability to disclose acidosis } \\
\hline Sensitivity $(\%)^{+}$ & $100 \%$ & - & $100 \%$ & - & - \\
\hline Specificity $(\%)^{+}$ & $62 \%$ & - & $80 \%$ & - & - \\
\hline
\end{tabular}

$\mathrm{SIG}=$ strong ion gap; $\mathrm{SID}_{\mathrm{a}}=$ apparent strong ion difference; $\mathrm{A}=$ albumin; $\mathrm{P}_{\mathrm{i}}=$ inorganic phosphorus. * The sum $\mathrm{A}+\mathrm{P}_{\mathrm{i}}$ was normal in these measurements . $\mathrm{N}(\%)$ indicates the number of measures considering the characteristic and the representative percentage relative to the number of measures for a given SBE cut-off or the total number of measures. ${ }^{+}$These values were calculated using the physicochemical criteria as the "gold standard" to disclose metabolic acidosis. 
Table 4. Sensitivity, specificity, and accuracy of $A G_{A}$ and $A G_{A+P}$ to predict elevated level of unmeasured anions (SIG >6.1 mEq/L).

\begin{tabular}{|c|c|c|c|c|c|c|c|c|c|c|}
\hline & \multicolumn{2}{|c|}{ All 62 measurements } & \multicolumn{2}{|c|}{$\mathrm{SBE}_{\mathrm{vs}}<-5 \mathrm{mEq} / \mathrm{L}(\mathrm{N}=38)$} & \multicolumn{2}{|c|}{$\mathrm{SBE}_{\mathrm{Vs}}<-2 \mathrm{mEq} / \mathrm{L}(\mathrm{N}=48)$} & \multicolumn{2}{|c|}{$\mathrm{SBE}_{\mathrm{vs}} \geq-5 \mathrm{mEq} / \mathrm{L}(\mathrm{N}=24)$} & \multicolumn{2}{|c|}{$\mathrm{SBE}_{\mathrm{Vs}} \geq-2 \mathrm{mEq} / \mathrm{L}(\mathrm{N}=14)$} \\
\hline \multirow[t]{2}{*}{$\begin{array}{l}\text { Measurements w } \\
\mathrm{SIG}>6.1 \mathrm{mEq} / \mathrm{L} \text {, }\end{array}$} & \multicolumn{2}{|l|}{$\begin{array}{l}\text { ith } \\
N\end{array}$} & \multicolumn{2}{|c|}{35} & \multicolumn{2}{|c|}{44} & \multicolumn{2}{|c|}{18} & \multicolumn{2}{|c|}{9} \\
\hline & $\begin{array}{c}\mathrm{AG}_{\mathrm{A}}>19.6 \\
\mathrm{mEq} / \mathrm{L} \\
(\mathrm{N}=50)\end{array}$ & $\begin{array}{c}\mathrm{AG}_{\mathrm{A}+\mathrm{P}}>19 \\
\mathrm{mEq} / \mathrm{L} \\
(\mathrm{N}=36)\end{array}$ & $\begin{array}{c}\mathrm{AG}_{\mathrm{A}}>19.6 \\
\mathrm{mEq} / \mathrm{L} \\
(\mathrm{N}=35)\end{array}$ & $\begin{array}{c}\mathrm{AG}_{\mathrm{A}+\mathrm{P}}>19 \\
\mathrm{mEq} / \mathrm{L} \\
(\mathrm{N}=25)\end{array}$ & $\begin{array}{c}\mathrm{AG}_{\mathrm{A}}>19.6 \\
\mathrm{mEq} / \mathrm{L} \\
(\mathrm{N}=44)\end{array}$ & $\begin{array}{c}\mathrm{AG}_{\mathrm{A}+\mathrm{P}}>19 \\
\mathrm{mEq} / \mathrm{L} \\
(\mathrm{N}=34)\end{array}$ & $\begin{array}{c}\mathrm{AG}_{\mathrm{A}}>19.6 \\
\mathrm{mEq} / \mathrm{L} \\
(\mathrm{N}=16)\end{array}$ & $\begin{array}{c}\mathrm{AG}_{\mathrm{A}+\mathrm{P}}>19 \\
\mathrm{mEq} / \mathrm{L} \\
(\mathrm{N}=11)\end{array}$ & $\begin{array}{c}\mathrm{AG}_{\mathrm{A}}>19.6 \\
\mathrm{mEq} / \mathrm{L} \\
(\mathrm{N}=7)\end{array}$ & $\begin{array}{c}\mathrm{AG}_{\mathrm{A}+\mathrm{P}}>19 \\
\mathrm{mEq} / \mathrm{L} \\
(\mathrm{N}=2)\end{array}$ \\
\hline Sensitivity (\%) & $94 \%$ & $85 \%$ & $97 \%$ & $69 \%$ & $98 \%$ & $75 \%$ & $89 \%$ & $61 \%$ & $78 \%$ & $22 \%$ \\
\hline Specificity (\%) & $89 \%$ & $89 \%$ & $67 \%$ & $67 \%$ & $75 \%$ & $75 \%$ & $100 \%$ & $100 \%$ & $100 \%$ & $100 \%$ \\
\hline $\begin{array}{l}\text { Accuracy - AUC } \\
(95 \% \mathrm{Cl})\end{array}$ & $\begin{array}{c}0.889 \\
(0.688-1.090)\end{array}$ & $\begin{array}{c}0.889 \\
(0.688-1.090)\end{array}$ & $\begin{array}{c}0.676 \\
(0.157-1.195)\end{array}$ & $\begin{array}{c}0.676 \\
(0.157-1.195)\end{array}$ & $\begin{array}{c}0.756 \\
(0.341-1.171)\end{array}$ & $\begin{array}{c}0.756 \\
(0.341-1.171)\end{array}$ & $\begin{array}{c}0.991 \\
(0.962-1.020)\end{array}$ & $\begin{array}{c}0.991 \\
(0.962-1.020)\end{array}$ & $\begin{array}{c}1.000 \\
(1.000-1.000)\end{array}$ & $\begin{array}{c}1.000 \\
1.000-1.000)\end{array}$ \\
\hline
\end{tabular}

$S_{B} E_{V S}$ denotes standard base excess calculated with Van Slyke's equation. SIG denotes strong ion gap. $A_{A}$ denotes anion gap corrected for albumin. $A G_{A+P}$ denotes anion gap corrected for albumin and phosphate. AUC denotes the area under the ROC curve, and $\mathrm{Cl}$ denotes confidence interval.

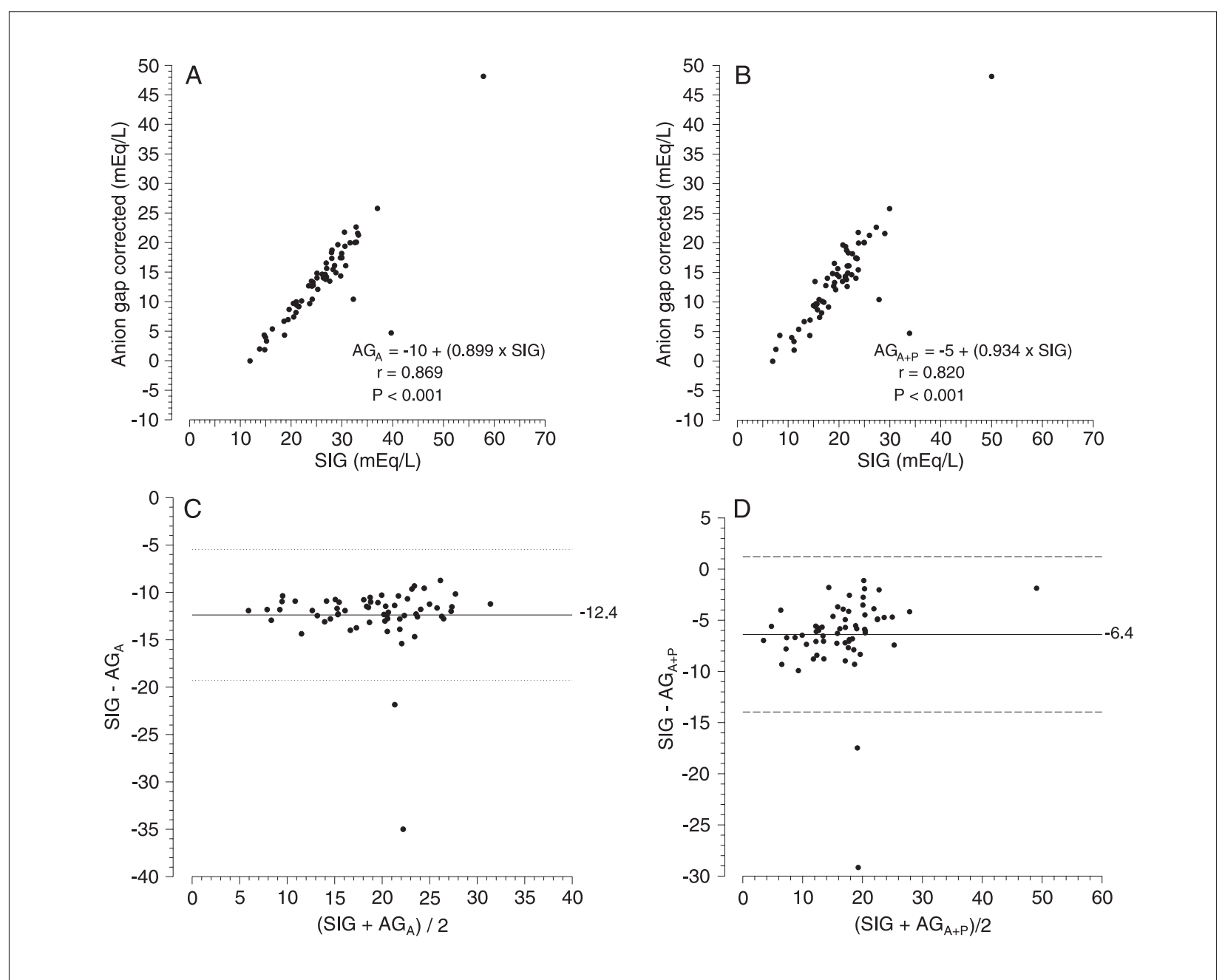

Figure 3. Correlation and agreement between the strong ion gap (SIG) and the anion gap corrected for albumin $\left(A_{A}\right)$ and correlation and agreement between SIG and the anion gap corrected for albumin and phosphate $\left(A G_{A+P}\right)$. $A$ and $B$ show the correlation and the linear regression model between SIG and $A G_{A}$ and $A G_{A+P}$, respectively. $C$ and $D$ show the Bland Altman plot with the agreement between $S I G$ and $A G_{A}$ and $A G_{A+P}$, respectively. The numbers shown on the right side of each plot are the bias. 
Table 5. Correlation between total sequential organ failure assessment score (SOFA) and acid-base variables.

\begin{tabular}{lcr}
\hline Variable & $r$-Spearman coefficient & P value \\
\hline SBE $_{V S}$ & -0.454 & $<0.001$ \\
$\mathrm{SBE}_{W}$ & -0.482 & $<0.001$ \\
$\mathrm{SIG}$ & 0.159 & 0.237 \\
$\mathrm{SID}$ & -0.156 & 0.244 \\
$\mathrm{AG}_{\mathrm{A}}$ & 0.247 & 0.064 \\
$\mathrm{AG}_{\mathrm{A}+\mathrm{P}}$ & 0.117 & 0.391 \\
$\mathrm{Albumin}_{\mathrm{P}} \mathrm{P}_{\mathrm{i}}$ & -0.097 & 0.472 \\
$\mathrm{PaCO}_{2}$ & -0.007 & 0.958 \\
\hline
\end{tabular}

$\mathrm{SBE}_{\mathrm{VS}}$ and $\mathrm{SBE}_{\mathrm{W}}=$ standard base excess calculated by Van Slyke and Wooten equations, respectively; $\mathrm{SIG}=$ strong ion gap; $\mathrm{SID}_{\mathrm{a}}=$ apparent strong ion difference; $\mathrm{AG}_{\mathrm{A}}=$ anion gap corrected for albumin; $\mathrm{P}_{\mathrm{i}}=$ inorganic phosphorus.

We performed an analysis in which we attempted to correlate the SBE obtained from the patient with the total SOFA on the same day. A correlation of $r=-0.454(P<$ 0.001 ) was shown between the $\mathrm{SBE}_{\mathrm{VS}}$ and the total SOFA, and a correlation of $r=-0.482(P<0.001)$ was shown between the $\mathrm{SBE}_{\mathrm{W}}$ and the total SOFA (Table 5). With 62 blood samples, there was a statistically significant correlation between the SBE and the total SOFA, showing that the SBE value can be used as a reflection of the disease severity of a critically ill patient (Table 5). In view of the correlation with clinical outcome and severity, SBE can be a reliable tool to diagnose metabolic acidosis $(8,9,11)$.

Methods used to calculate standard base excess

Since the initial description of SBE (2), mathematical approaches have been described that simplify the SBE calculation $(3,23,24)$. The SBE is a derivation of the base excess, in which the base excess equation is modified to standardize the effect of hemoglobin and improve the accuracy of base excess. Currently, the commercially available arterial blood gas machine calculates base excess using a 14-variable equation (3). In addition, although base excess is quite accurate in vitro, inaccuracy has always been a problem when applied in vivo in that base excess changes slightly with changes in $\mathrm{PaCO}_{2}$. This effect is thought to be due to equilibration across the entire extracellular fluid space. Thus, the base excess equation was modified to standardize the effect of hemoglobin in order to improve the accuracy of base excess in vivo (25).

The SBE calculation by Van Slyke's method still yields results that are slightly unstable as the $\mathrm{PaCO}_{2}$ changes (25). Furthermore, the equation assumes normal levels of weak acids (i.e., phosphate + albumin) $(3,26)$. Further instability results when albumin or phosphate is decreased, as commonly occurs in critically ill patients $(4,27)$. Recently, Wooten developed a multi-compartment model using quantitative techniques and suggested a correction for SBE that results in a formula for SBE that agrees much more closely with experimental data in humans $(23,24)$. To date, uncertainty about the appropriate method persists, in addition to the fact that many of the commercially available arterial blood gas machines calculate SBE using Van Slyke's equation.

By analyzing the differences between $\mathrm{SBE}_{\mathrm{vs}}$ and $\mathrm{SBE}_{\mathrm{W}}$, we found that their accuracy in predicting metabolic acidosis was quite similar (Figure 1) and that they were both clinically and statistically equivalent (Table 2 and Figure 1 ) with respect to all categorized cut-off values of $\mathrm{SBE}_{\mathrm{Vs}}$, as both correlated well $(r=0.992, \mathrm{P}<0.001)$ and had good agreement (bias, $0.816 \mathrm{mEq} / \mathrm{L}$; limits of agreement, -2.216 to $0.584 \mathrm{mEq} / \mathrm{L}$; Figure 1). As stated, the $\mathrm{SBE}_{\mathrm{Vs}}$ and the $\mathrm{SBE}_{W}$ were similarly correlated with the severity of the acute disease (SOFA score; Table 5). Since it is much easier to obtain the $\mathrm{SBE}_{\mathrm{VS}}$ from standard blood gas analyzers, and since $\mathrm{SBE}_{\mathrm{Vs}}$ and $\mathrm{SBE}_{\mathrm{W}}$ are numerically and clinically interchangeable, the $\mathrm{SBE}_{\mathrm{Vs}}$ can be used at the bedside in a safe and easy way.

\section{Standard base excess cut-off value to identify metabolic acidosis}

The next parameter to identify patients with metabolic acidosis was the best cut-off value of $\mathrm{SBE}_{\mathrm{vs}}$. Some consider a value of $\mathrm{SBE}_{\mathrm{Vs}}<-5 \mathrm{mEq} / \mathrm{L}$ (3) to be useful, while others use an $\mathrm{SBE}_{\mathrm{Vs}}<-2 \mathrm{mEq} / \mathrm{L}(6,7)$. Considering the value of $\mathrm{SBE}_{\mathrm{Vs}}<-5 \mathrm{mEq} / \mathrm{L}$, we observed that many variables related to acid-base metabolism were different between the groups with $\mathrm{SBE}_{\mathrm{vs}}$ measurements $>2$ and <-5 $\mathrm{mEq} / \mathrm{L}$ (Table 2). Some variables were statistically equivalent when the $\mathrm{SBE}_{\mathrm{vs}}$ cut-off was changed to $-2 \mathrm{mEq} / \mathrm{L}$, such as albumin, albumin $+\mathrm{P}_{\mathrm{i}}$, creatinine, and SID $_{\mathrm{a}}$ (Table 2 ). In contrast, the clinical relevance of these findings did not seem to be important. Considering the physicochemical approach as the reference to diagnose acid-base disturbances, the $\mathrm{SBE}_{\mathrm{Vs}}$ cut-off of $-5 \mathrm{mEq} / \mathrm{L}$ and the $\mathrm{SBE}_{\mathrm{Vs}}$ cut-off of $-2 \mathrm{mEq} / \mathrm{L}$ were both able to identify $100 \%$ of measures with metabolic acidosis (Table 3 ).

Partitioning the metabolic acidosis as proposed by Stewart (1), an $\mathrm{SBE}_{\mathrm{VS}}<-5 \mathrm{mEq} / \mathrm{L}$ was able to identify 35 of $53(66 \%)$ measures with SIG acidosis, while an $\mathrm{SBE}_{\mathrm{Vs}}<-2$ $\mathrm{mEq} / \mathrm{L}$ was able to identify 44 of 53 (84\%) measures with SIG acidosis (Table 3). An $\mathrm{SID}_{a}$ acidosis was similarly identified by the two $\mathrm{SBE}_{\mathrm{Vs}}$ cut-offs, with 20 of 24 (84\%) identified with an $\mathrm{SBE}_{\mathrm{Vs}}<-5 \mathrm{mEq} / \mathrm{L}$ and 21 of $24(89 \%)$ identified with an $\mathrm{SBE}_{\mathrm{vs}}<-2 \mathrm{mEq} / \mathrm{L}$ (Table 3). Thus, the identification of SIG acidosis appears to be a valid clinical 
outcome marker (7-9). There are no measurements with acidosis determined by weak acids (albumin $+\mathrm{P}_{\mathrm{i}}$; Table 3 ). The capacity to disclose more measures with SIG acidosis, besides the non-significant differences in other variables related to acid-base metabolism, makes the value of $\mathrm{SBE}_{\mathrm{Vs}}$ $<-2 \mathrm{mEq} / \mathrm{L}$ a good reference value to be used at the bedside in identifying metabolic acidosis in critically ill patients.

\section{Evaluation of unmeasured anions}

Hyperchloremic $\left(\mathrm{SID}_{\mathrm{a}}\right)$ acidosis is experimentally associated with low renal blood flow (10), inflammation (28), and death (29). These findings are not associated with clinical outcomes, however (7). By contrast, SIG acidosis is related to prognosis in humans $(7,8)$ and its theoretical surrogate, $A G$, is also related to outcomes (8). As recently described, AG is correlated and agrees well with SIG when corrected by weak acids (7). We tested SIG with AG corrected for albumin $\left(\mathrm{AG}_{\mathrm{A}} ; \mathrm{r}=0.869, \mathrm{P}<0.001\right.$, bias, -12.4 $\mathrm{mEq} / \mathrm{L}$, and limits of agreement, -15.84 to $-8.94 \mathrm{mEq} / \mathrm{L}$; Figure 2) and SIG with $A G$ corrected for albumin and phosphate $\left(A G_{A+P} ; r=0.820, P<0.001\right.$, bias, $-6.4 \mathrm{mEq} / \mathrm{L}$, and limits of agreement, -14.1 to $1.3 \mathrm{mEq} / \mathrm{L}$; Figure 2 ). The correlation between $A G_{A}$ and $S I G$ was similar to the $A G_{A+P}$.

The Bland-Altmann plot agreement showed that the bias between $A_{A}$ and SIG was superior to the bias between $A G_{A+P}$ and SIG, which is consistent with the concept that the $A G_{A+P}$ is actually a rough SIG rather than an anion gap (3). The dispersion of the individual differences between AG corrected and SIG on the graph was quite similar between $A G_{A}$ and $A G_{A+P}$ (Figure 2). By contrast, $A G_{A}$ was more sensitive to disclose unmeasured anions than $A G_{A+P}$, but with the same accuracy when all measurements were taken into account (Table 4). This higher sensitivity of $A G_{A}$ to disclose unmeasured anions was especially striking with $\mathrm{SBE}_{\mathrm{VS}}<-2 \mathrm{mEq} / \mathrm{L}$ (98\%), while the sensitivity of $\mathrm{AG}_{\mathrm{A}+\mathrm{P}}$ was

\section{References}

1. Stewart PA. Modern quantitative acid-base chemistry. Can J Physiol Pharmacol 1983; 61: 1444-1461.

2. Astrup $\mathrm{P}$, Jorgensen K, Andersen OS, Engel K. The acidbase metabolism. A new approach. Lancet 1960; 1: 10351039.

3. Kellum JA. Clinical review: reunification of acid-base physiology. Crit Care 2005; 9: 500-507.

4. Fencl V, Jabor A, Kazda A, Figge J. Diagnosis of metabolic acid-base disturbances in critically ill patients. Am J Respir Crit Care Med 2000; 162: 2246-2251.

5. Kellum JA. Determinants of blood pH in health and disease. Crit Care 2000; 4: 6-14.
$75 \%$ despite the same non-significant accuracy (Table 4). It is easier to calculate $A G_{A}$ than $A G_{A+P}$ and $S I G(4)$, and $A G_{A}$ is very sensitive in detecting SIG acidosis. Thus, it is a useful tool to detect unmeasured anions in critically ill patients.

In practice, the $\mathrm{SBE}_{\mathrm{Vs}}$ can be in a normal range with a low $\operatorname{SID}_{\mathrm{a}}$ and a low albumin (albumin $+\mathrm{P}_{\mathrm{i}}$ ), which is a common finding in critically ill patients. In this situation, some have considered a low $\operatorname{SID}_{\mathrm{a}}$ to be an adaptation to a low albumin level, rather than a complex acid-base disturbance (5). Our patients had the stated low levels of SIDa and albumin, and an alternative interpretation of our data is that the low $\operatorname{SID}_{\mathrm{a}}$ was appropriate for the scenario.

\section{Metabolic determinants of standard base excess variations}

Considering the $\mathrm{SBE}_{\mathrm{vs}}$ to be an appropriate tool to diagnose metabolic acidosis, and that the metabolic component of acid-base derangements correlated quite well with strong ions, unmeasured anions, lactate concentration, and weak acids $(1,4)$, we constructed five models of $\mathrm{SBE}_{\mathrm{Vs}}$ variation determinants. It is clear that the first model (i.e., the model with the Stewart's variables) fits very well with the $\mathrm{SBE}_{\mathrm{Vs}}$ variations, showing the importance of Stewart's physicochemical quantitative approach (1). In order to facilitate this approach at the bedside, the fifth model considered some variables that use simple calculations (i.e., $\mathrm{AG}_{\mathrm{A}}, \mathrm{SID}_{\mathrm{a}}$, albumin level, and lactate concentration) and fits quite well with the $\mathrm{SBE}_{\mathrm{vs}}$ variations.

In conclusion, our study showed that the $\mathrm{SBE}_{\mathrm{VS}}$ with a cut-off value <-2 $\mathrm{mEq} / \mathrm{L}$ was the best tool to diagnose metabolic acidosis. In analyzing the components of the $\mathrm{SBE}_{\mathrm{VS}}$ shifts at the bedside, the $\mathrm{AG}_{\mathrm{A}}$, the $\mathrm{SID}_{\mathrm{a}}$, the albumin level, and the lactate concentration are easily obtainable variables that represent the partitioning of physicochemical quantitative analyses of acid-base derangements.

6. Gunnerson KJ. Clinical review: the meaning of acid-base abnormalities in the intensive care unit part I - epidemiology. Crit Care 2005; 9: 508-516.

7. Gunnerson KJ, Saul M, He S, Kellum JA. Lactate versus non-lactate metabolic acidosis: a retrospective outcome evaluation of critically ill patients. Crit Care 2006; 10: R22.

8. Kaplan LJ, Kellum JA. Initial pH, base deficit, lactate, anion gap, strong ion difference, and strong ion gap predict outcome from major vascular injury. Crit Care Med 2004; 32: 1120-1124.

9. Balasubramanyan N, Havens PL, Hoffman GM. Unmeasured anions identified by the Fencl-Stewart method predict 
mortality better than base excess, anion gap, and lactate in patients in the pediatric intensive care unit. Crit Care Med 1999; 27: 1577-1581.

10. Wilcox CS. Regulation of renal blood flow by plasma chloride. J Clin Invest 1983; 71: 726-735.

11. Smith I, Kumar P, Molloy S, Rhodes A, Newman PJ, Grounds RM, et al. Base excess and lactate as prognostic indicators for patients admitted to intensive care. Intensive Care Med 2001; 27: 74-83.

12. Kajdacsy-Balla Amaral AC, Andrade FM, Moreno R, Artigas $A$, Cantraine $F$, Vincent JL. Use of the sequential organ failure assessment score as a severity score. Intensive Care Med 2005; 31: 243-249.

13. Vincent JL, Moreno R, Takala J, Willatts S, De Mendonca A, Bruining $\mathrm{H}$, et al. The SOFA (Sepsis-related Organ Failure Assessment) score to describe organ dysfunction/failure. On behalf of the Working Group on Sepsis-Related Problems of the European Society of Intensive Care Medicine. Intensive Care Med 1996; 22: 707-710.

14. Moreno R, Vincent JL, Matos R, Mendonca A, Cantraine F, Thijs $L$, et al. The use of maximum SOFA score to quantify organ dysfunction/failure in intensive care. Results of a prospective, multicentre study. Working Group on Sepsis related Problems of the ESICM. Intensive Care Med 1999; 25: 686-696.

15. De Mendonca A, Vincent JL, Suter PM, Moreno R, Dearden $\mathrm{NM}$, Antonelli M, et al. Acute renal failure in the ICU: risk factors and outcome evaluated by the SOFA score. Intensive Care Med 2000; 26: 915-921.

16. Antonelli M, Moreno R, Vincent JL, Sprung CL, Mendoça A, Passariello M, et al. Application of SOFA score to trauma patients. Sequential Organ Failure Assessment. Intensive Care Med 1999; 25: 389-394.

17. Povoa P, Coelho L, Almeida E, Fernandes A, Mealha R, Moreira $\mathrm{P}$, et al. Early identification of intensive care unitacquired infections with daily monitoring of C-reactive protein: a prospective observational study. Crit Care 2006; 10:
R63.

18. Ferreira FL, Bota DP, Bross A, Melot C, Vincent JL. Serial evaluation of the SOFA score to predict outcome in critically ill patients. JAMA 2001; 286: 1754-1758.

19. Wooten EW. Calculation of physiological acid-base parameters in multicompartment systems with application to human blood. J Appl Physiol 2003; 95: 2333-2344.

20. Wooten EW. Analytic calculation of physiological acid-base parameters in plasma. J Appl Physiol 1999; 86: 326-334.

21. Murray DM, Olhsson V, Fraser JI. Defining acidosis in postoperative cardiac patients using Stewart's method of strong ion difference. Pediatr Crit Care Med 2004; 5: 240-245.

22. Brackett NC Jr, Cohen JJ, Schwartz WB. Carbon dioxide titration curve of normal man. Effect of increasing degrees of acute hypercapnia on acid-base equilibrium. $N$ Engl $J$ Med 1965; 272: 6-12.

23. Morgan TJ, Clark C, Endre ZH. Accuracy of base excess an in vitro evaluation of the Van Slyke equation. Crit Care Med 2000; 28: 2932-2936.

24. Figge J, Jabor A, Kazda A, Fencl V. Anion gap and hypoalbuminemia. Crit Care Med 1998; 26: 1807-1810.

25. Kellum JA, Song M, Li J. Lactic and hydrochloric acids induce different patterns of inflammatory response in LPSstimulated RAW 264.7 cells. Am J Physiol Regul Integr Comp Physiol 2004; 286: R686-R692.

26. Kellum JA. Fluid resuscitation and hyperchloremic acidosis in experimental sepsis: improved short-term survival and acid-base balance with Hextend compared with saline. Crit Care Med 2002; 30: 300-305.

27. Figge J, Mydosh T, Fencl V. Serum proteins and acid-base equilibria: a follow-up. J Lab Clin Med 1992; 120: 713-719.

28. Figge $\mathrm{J}$, Rossing $\mathrm{TH}$, Fencl $\mathrm{V}$. The role of serum proteins in acid-base equilibria. J Lab Clin Med 1991; 117: 453-467.

29. Kellum JA, Kramer DJ, Pinsky MR. Strong ion gap: a methodology for exploring unexplained anions. J Crit Care 1995; 10: 51-55.

\section{Appendix}

Standard base excess (Van Slyke's equation) $\left(\mathrm{SBE}_{\mathrm{VS}}\right)(\mathrm{mEq} / \mathrm{L})=0.9287 \times\left(\mathrm{HCO}_{3}{ }^{-}-24.4+14.83 \times \mathrm{pH}-7.4\right)$

Standard base excess (Wooten's equation) $\left(\mathrm{SBE}_{W}\right)(\mathrm{mEq} / \mathrm{L})=\left(\mathrm{HCO}_{3}^{-}-24.4\right)+((8.3 \times$ albumin $(\mathrm{g} / \mathrm{dL}) \times 0.15)+(0.29 \times \mathrm{phosphate}(\mathrm{mg} / \mathrm{dL}) \times 0.32)) \times \mathrm{pH}-7.4$

Anion gap (corrected for albumin) $\left(\mathrm{AG}_{\mathrm{A}}\right)(\mathrm{mEq} / \mathrm{L})=\left(\mathrm{Na}^{+}+\mathrm{K}^{+}\right)-\left(\mathrm{Cl}^{-}+\mathrm{HCO}_{3}{ }^{-}\right)+2.5 \times(4-\operatorname{albumin}(\mathrm{g} / \mathrm{dL}))$

Anion gap (corrected for albumin and phosphate) $\left(\mathrm{AG}_{\mathrm{A}+\mathrm{P}}\right)(\mathrm{mEq} / \mathrm{L})=\left(\mathrm{Na}^{+}+\mathrm{K}^{+}\right)-\left(\mathrm{Cl}^{-}+\mathrm{HCO}_{3}^{-}\right)-(2 \times$ albumin $(\mathrm{g} / \mathrm{dL})+0.5 \times \mathrm{phosphate}(\mathrm{mg} / \mathrm{dL}))$

Apparent strong ion difference $\left(\mathrm{SID}_{\mathrm{a}}\right)(\mathrm{mEq} / \mathrm{L})=\mathrm{Na}^{+}+\mathrm{K}^{+}+\mathrm{Ca}^{2+}+\mathrm{Mg}^{2+}-\mathrm{Cl}^{-}$

Effective strong ion difference $\left(\mathrm{SID}_{\mathrm{e}}\right)(\mathrm{mEq} / \mathrm{L})=2.46 \times 10^{-8} \times \mathrm{PCO}_{2} / 10^{-\mathrm{pH}}+($ albumin $(\mathrm{g} / \mathrm{dL})) \times(0.123 \times \mathrm{pH}-0.631)+(\mathrm{phosphate}(\mathrm{mg} / \mathrm{dL}) / 3 \times \mathrm{pH}-0.469)$

$\mathrm{SIG}(\mathrm{mEq} / \mathrm{L})=\mathrm{SID}_{\mathrm{a}}-\mathrm{SID}_{\mathrm{e}}$

Albumin $(\mathrm{mEq} / \mathrm{L})=10 \times$ albumin $(\mathrm{g} / \mathrm{dL}) \times(0.123 \times \mathrm{pH}-0.631)$

Inorganic phosphate $\left(\mathrm{P}_{\mathrm{i}}\right)(\mathrm{mEq} / \mathrm{L})=\left(\mathrm{PO}_{4}(\mathrm{mg} / \mathrm{dL}) \times 10 / 30.97\right) \times(0.309 \times \mathrm{pH}-0.469)$

The unit of all strong ions was $\mathrm{mEq} / \mathrm{L}$. 